\title{
UNDERSTANDING THE PARENTAL CHALLENGES IN RAISING AUTISM CHILDREN
}

\author{
Naziah Binti Abd Kadir \\ Faculty of Education and Social Sciences, University Selangor, Jalan Timur Tambahan, \\ 45600 Bestari Jaya, Selangor, Malaysia.
}

*Corresponding Author email: nazya 87@yahoo.com

Article History

Submission: May 12, 2020

Revised: June 05, 2020

Accepted: June 20, 2020

\begin{abstract}
Throughout the world, many children are diagnosed with Autism Spectrum Disorder (ASD). There are many challenges parents face in raising these special children. It includes the educational, financial, social and mental aspects of the parents themselves. Even parents with autism children are said to suffer more stress than parents with normal children or other disabilities. This article is intended to gain a better understanding of the major challenges parents face in autism children. Based on the reading and observation, parents found that children with autism had their own challenges in raising their children. They need the support and concern of all parties to stay strong for their children. At the end of this article is the hope that the parental voice can be addressed. Also, this service can inspire parties such as government departments, NGO's and the rest of the community to come up with a program or support plan that can help parents and children with autism. This study uses qualitative methods in which the researcher will conduct semi-structured interviews to understand the meaning given by the respondents on this issue.
\end{abstract}

Keywords: Autism; Parental Challenges; Special Children

Abbreviations: Nil

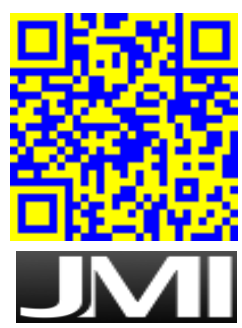

Journal of Management Info. Vol. 7 No. 2, 2020: pp. 62-75 Doi: 10.31580/jmi.v7i2.1419 www.readersinsight.net/jmi

\section{INTRODUCTION}

Autism Spectrum Disorders is a form of long-term developmental disorder that affects children's thinking and information processing (myhealth.gov.my, 2008). It also involves problems with the development of nerves that can be seen from non-verbal behaviour and communication. For example, an autism child will never see or make eye contact with someone who is talking to them.

\section{Readers /nsight}


The disruption of the structure and function of the brain and nervous system affects an individual's social skills. It also affects his ability to communicate well. One of the notable features of autism children is the limited number of behavior and interests (American Psychiatric Association, 2013).

Autism can be detected as early as 1 year old if the symptoms of developmental delay are too high. However, if the symptoms of the disorder are not clear, autism can usually be detected when the child is between 2 and 3 years old (Centre for Disease Control, 2013).

Loss of communication (social and language) capabilities is a sign of the beginning. Children will begin to show less interest in social interactions in the first year of life (Paul \& Kimberly, 2011). In addition, autism symptoms tend to delay language development and are often associated with a lack of social interest. Or tend to interact in unusual ways, odd play styles and unusual communication patterns. In the second year, the tendency for repetitive behaviors and unusual game patterns will increase (Paul \& Kimberly, 2011).

As of May 2017, the Department of Social Welfare (JKM) has recorded 15,484 people diagnosed with autism across Malaysia. Of those, 2,080 were under the age of 6 . A total of 7,167 people are aged 7 to 12 and 2,248 are between the ages of 13 and 18 (astroawani.com, 2018).

In 2008, a national study in the United States reported that 1 in 88 children aged 8 years was diagnosed with Autism Spectrum Disorders (ASD). This study was conducted in 14 different communities in the United States. Meanwhile, in 2012, the French Ministry of Health estimates that one out of every 150 people in the country has autism. In 2013, the National Association of Autism of Malaysia (Nasom) presented statistics that out of every 500 children, one of them has autism (Utusan Online, 2013).

\section{SIGNS OF IDENTIFYING AUTISM CHILDREN}

According to the Ministry of Health Malaysia, the symptoms of autism in a child can be seen through three main aspects of communication, social reactions and repeated behavior in terms of interests and activities.

This aspect of communication refers to the problem of interaction between an autism sufferer and the person around them. This can be seen from slow speech, abnormal or even inability to speak. They also have abnormal body language such as lack of movement of the limbs. Children with autism are also often less intelligent during play time and less able to interact and communicate with others (myhealth.gov.com, 2008). 
From a social point of view, autism children tend to be alone in most cases. They have no interest in playing with their friends and only in their world. This causes them to lose awareness of others and even lose focus on the people around them. This also makes them less likely to have the same facial expressions as other normal children (myhealth.gov.com, 2008).

Touching on the tendency to act over and over again, children with autism will often clap, sway back and forth or nod their heads. They are also usually only interested in one or two things. For example, when playing, their interest will be focused on rotating car tires. If someone stops or takes the car, they will feel very depressed (myhealth.gov.my, 2008).

To recognize these signs, parents need to take the time to monitor their children's development from a young age. This is because most experts acknowledge that the symptoms of autism will only start when they are 2 years old, but according to Deanna Chee (a graduate of early childhood education), the symptoms of autism can be identified as early as 5 or 6 months old again (theproparenting.com). The signs in question are as follows:

\section{a) Slow Motor Development}

- For a 6-month-old baby, she doesn't know how to smile or express her happiness.

- For a 9-month-old baby, she does not make any noise or mimic facial expressions.

- For a 12-month-old baby, he doesn't want to talk or respond to people's calls.

b) Wanting Extra Attention

- It's normal if a baby refuses to be with another person. But parents need to pay closer attention. If the traits are still the same as the child ages, precautions should be taken. It is possible that the baby has autism.

\section{c) Less Moving}

- Babies at the age of 8 months or at least 10 months should have their motor development developed. They should already be able to reach and hold an object. If there are signs such as a baby refusing to make a move, parents should take note.

d) No Baby Talk

- Baby talk is a conversation the baby uses in their own language. Usually when they are 12 months old (1 year) they start to sound like they want to chat. For example emm, baa, maaa. Baby autism cannot produce the sound. It makes it 
difficult for them to express their wishes and understand the meaning of a command.

\section{e) Not Responding When Called}

- $\quad$ Autism infants don't enjoy interacting with other people. They'll feel a kiss or a kiss. If the baby is between 5 and 12 years old but still does not respond when his name is called, parents should pay more attention to the baby.

\section{f) No Eye-Contact}

- The autism baby does not respond to any movements that occur in front of him. It is different from the normal baby who will look at the object. Observing this eye-contact reaction is the easiest way to identify infants with autism.

\section{g) It's Hard to Smile}

- At 6 months of age and older, babies usually start to smile. They can also do faceto-face mimicry with anyone around them. However, there are also cases where there are infants who cannot smile and do not react even when asked. This could be an indication that the baby may have autism.

\section{AutISM COMPLICATIONS TOWARDS CHILD'S LIFE}

Each person with autism will have different symptoms according to their age. In the early stages of childhood, they often appear hyperactive and display heat-burning properties. In the later stages of childhood they are more likely to be aggressive and able to injure themselves and attack others.

If these autism children are not treated properly and do not receive proper education early on, they may face more chronic problems such as depression and epilepsy from adolescence through adulthood (myhealth.gov.com, 2008).

In addition to the aforementioned complications, children with autism may also have problems with the digestive system, sleep patterns or eating patterns that are different from other normal children. They are also exposed to the risk of developing tuberous sclerosis, which is a disease that promotes tumor growth in the body including the brain (alodokter.com, 2018).

\section{THE CAUSES OF AUTISM}

Basically, researchers and physicians consider that the main cause for autism is genetic. However, they still do not understand how clear the relationship is. This also limits the ability to find appropriate ways to prevent children from getting autism.

There is also a theory that autism occurs due to the unhealthy lifestyle practices adopted by the mother during pregnancy. These include smoking, alcoholic beverages 
and drug abuse. Exposure to natural pollutants containing metals is also said to be affecting fetal health and increasing the risk of autism and other serious problems (Dr M Ramzdhan, doctoroncall.com.my, 2019).

According to an article on theasianparent.com portal, experts have rejected the possibility of autism disorders stemming from vaccines. However, some say that the level of diabetes in the mother also affects the risk of developing autism. In addition, unhealthy maternal conditions during pregnancy or childbirth can be said to be the cause.

However, a pediatric counselor, Dr. Harvey Karp has his own theory on this issue. According to her, pregnancy exposure to endocrine chemicals (EDCs) found in many home appliances is very dangerous. The simplest example of endocrine chemistry is the BPA found in baby milk bottles.

The World Health Organization (WHO) states that endocrine chemicals have the ability to alter and affect human reproductive function. In addition to being believed to increase the risk of breast cancer, endocrine chemicals are also said to disrupt the growth and immune system of children. It can enter the baby's brain system as well as the fetus and change their brain development (theasianparent.com).

\section{LITERATURE REVIEW}

As a parent, you've probably spent a lot of time thinking about your child's future, moreover if he or she has an autism spectrum disorder, or ASD diagnosis. Autism spectrum disorders are a series of related developmental disorders that can affect language skills, behavior, social interactions, and the ability to learn. The correct diagnosis early on helps children get the right treatment so they don't miss out on important development and learning. People with these conditions can have successful, happy lives. Keep an eye on how your child pays attention. Those with autism struggle to focus on things that they don't like, such as reading a book or doing a puzzle. And they may fixate on things that they do like, such as playing with a particular toy. (Shin Ying Chu Et Al, 2018)

Parents of children with autism sometimes describe feeling 'overwhelmed, guilty, confused, and angry or depressed'. Frustration is a common emotion. They may feel frustrated when their child is clumsy, unresponsive, angry or disregarding of others. (www.medicalnewstoday.com) 


\section{DifFICULTIES FACED by PARENTS}

Having an autism child is not a tragedy. Rather, it is a priceless gift for selected parents. However, it is undeniable that there are many challenges that parents need to face in order to ensure that their disabled children can continue to live their lives better.

Based on observations and readings, one of the main challenges that parents often face is their children's autism, finances and community acceptance. Each of these challenges can be classified as follows:

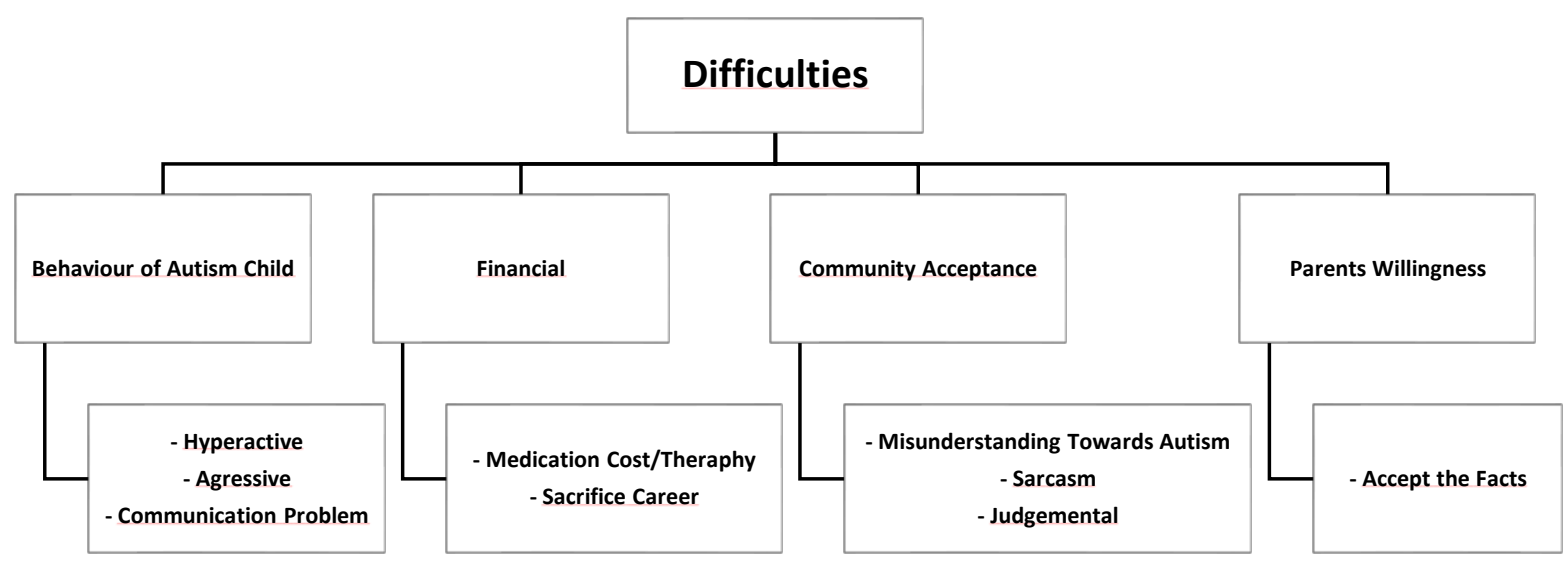

Fig. 1: Key challenges faced by parents in autism children

\section{Behavior of Autism Children}

Managing autism is a big challenge for parents. They are not like other normal children who can take care of themselves and listen well. The main challenges parents face with autism children are hyperactive, aggressive attitudes and communication problems in which these autism children find it difficult to communicate verbally or nonverbal and overly sensitive.

Hyperactive behavior usually referred to the condition of autism children who are constantly in control. They would run around, toss things, not sit still for a moment and often lose themselves. There are many instances of missing autism children in public places especially supermarkets due to this hyperactive behaviour. This is very worrying and requires parents to always be on the lookout for their children to be with them. In some cases, this situation can be very stressful especially if the parents have important matters that need to be resolved.

Excessive attention to these hyperactive autistic children can sometimes cause other siblings to feel uneasy. This is another challenge that parents have to face where they need to take time to explain to other children why their child needs more care. In these situations, there are parents who have to suppress emotions and try to be calmer. 
Aggressive behaviour refers to the attitudes of children with autism that have the potential to harm themselves and others. Parents and siblings are often the victims of their aggressive behaviour. Among the most common aggressive behavior are kicking, grabbing, and throwing things, choking, and pulling hair, banging their head and screaming with all their might.

The reactions mentioned above usually occur when their wishes are not met or they do not get what they want. It is a way for them to express their anger and dissatisfaction. However, it is very worrying for parents because extreme aggressive behaviour can hurt themselves and others around them.

Even more alarming is the fact that aggressive behaviour is shown to make siblings and other family members afraid to be close to the child. It causes emotional scars and can lead to more serious mental health problems.

The communication problems faced by autism children demand a great deal of patience from parents. They have a hard time speaking and expressing good will. Parents are not sure what they want. This led to dissatisfaction that eventually led them to act aggressively.

Communication problems also cause a 'gap' between the child and the siblings. Not a lot of people can understand what they are up to and how they are coping with the chaos they are facing. Therefore, only parents need to be there to be with them.

When it comes to over-sensitive behaviour, it is not an easy task for children with these overly sensitive sensory problems. They don't like the noise or the feeling of being uncomfortable. When they are in such a situation, they may run into hiding under the blanket or under the table or continue rolling around to express their dislike.

Such behaviour can occur anywhere including in the supermarket or other public places. This situation causes the parents' movement to be restricted because they have to try to avoid the environment that their child does not like. However, these autism children are a bit hard to imagine. Even if parents feel they are good enough, there may still be something wrong with them. Then there is the problem of children suddenly crying or raging for no reason. This can be a real challenge for parents without the support and encouragement.

\section{Financial}

Most parents will face this financial problem. The cost of treatment, medicine and therapy is not cheap. In fact, there are parents who say that autism is a disease of rich kid, illustrate that the financial provisions for the management of autism are large in number. 
There are parents who need to spend a significant amount of money to get treatment from private organizations or therapy centres for their children. To even see an expert they have to pay a certain amount of money first and the fee is not small. Parents need to make sacrifices to provide enough money for their child to receive good treatment.

But there are still parents who can't afford it. This is because some of them have to sacrifice their careers to focus on children who have been diagnosed with autism. If the husband and wife used to work, one might have to resign. Usually the wife will stop working to look after the child.

This has to some extent affected the family's financial situation. Spending not only on the treatment of autism children, but on other children should also be considered. They also need money for schooling and other matters. Due to this problem, some children with autism are unable to receive proper treatment. Not because parents don't want to, but they can't. They can only give up and hope for help so that their child can receive proper therapy.

\section{Community Acceptance}

Today, we are becoming more and more modern in terms of technology and everyday life. But in terms of thinking, there are still some of us who are trapped in ancient thought. They still see special children as a burden or a nuisance in society.

Many of the members of the community around us are unaware of the disorder that children with autism have. They do not realize that autism children look just like other normal children from the outside. Their interior is very different. Because of this lack of awareness, they are prone to misunderstandings.

There are several MITOS on autism circulating in society. These include:

- $\quad$ People with autism are considered aggressive and out of control.

- $\quad$ Autism is caused by bad parenting practices.

- Vaccination is one of the leading causes of autism syndrome.

- People with autism are unable to show compassion.

- Individuals with autism do not need learning in their lives. (astroawani.com, 2019)

Due to such misconceptions, society has moved away from families with autism. Parents have to endure in these difficult situations. There are parents who need to swallow the cynicism of their surroundings when their autism child starts rambling on the market. Some even scoff when they see parents still putting their grown-up children in the cart when shopping. It hurts when some of their own family members 
insist on saying that they are not good at educating children so that children are not good at talking even when they are supposed to go to school.

This hostile and easy-going demeanour has left many parents depressed and refrained from mixing with the community. Not many people are able to keep smiling when they are bullied and accused of being unwise. Especially when some people label these parents did not love their child because they have to isolate themselves in some cases.

Parental Willingness to Accept the Fact

Another challenge parents need to face is their own. The degree to which they are willing to accept the fact that a child is born is different from that of another. Are they strong enough to cope with the possibilities that come with their autism child?

These are questions that start to play in the minds of parents who know their child is different from other normal children. It is not an easy situation to face this fact especially if the child is the first child the family has long been waiting for. It requires a high degree of persistence for parents to stay calm and accept that fact with great sincerity.

Although children with autism are not the first child, they still demand high availability. To accept the fact, to explain it to other children and to make them understand that this autism child needs to be given more attention than the attention of the older brother or sister will be lessened. This is hard to do if parents are not prepared enough.

Without parental preparedness, there will be arguments and accusations. There are those who leave the couple alone and some continue to disown children. It would be very painful if it happened.

Parental readiness is the first challenge to overcome. Parents need to be emotionally and mentally prepared to raise autism children. Dealing with miscarriages, misunderstandings, daily routine changes, lack of rest and having to be vigilant can be very stressful. However, it can be very rewarding when there is positive development in the child.

\section{METHODOLOGY}

The structure of this study is a phenomenological research using semi-structured interviews conducted face-to-face to get feedback and information from respondents on the subject matter being studied. Qualitative phenomenological analysis explores concepts and provides additional insights into the subject matter studied that may not be possible through quantitative studies. Meanwhile, the use of structured semistructured interviews is intended to facilitate the development of research and research of the group. As a result, during the interview, researcher was able to identify 
the parental challenges in raising autism children. In this study, data are classified according to the theme based on the topics studied.

\section{RESEARCH SAMPLING:}

This study is qualitative in nature and statistical generalization is not the aim of this study. Therefore, probability sampling was not used in this study; instead, nonprobability sampling was used for the purpose of selecting samples for this study. Non-probability sampling is relevant to this study since the study was conducted to make findings on what was happening in the life of the parents with autism children, what are their challenges, financial aspects that they faced, the implications of what happened to the children and the relationship that relates to what happened in the context of parental challenges faced in raising autism children, rather than to answer questions such as "how much" and "how often" as in quantitative studies (Honigmann, 1982).

Therefore, the most appropriate sampling strategy used in this study is objective sampling (Patton, 2002). Purposive / purposeful sampling is based on the assumption that the researcher wants to find, understand, and get an idea of the subject of the study. Therefore, it is important for this study to select a sample that will help to understand the subject being studied (Merriam, 2009). According to Patton (2002), the logic and power of sampling is based on a case study that provides more information with in-depth information. Therefore, selection criteria are important in selecting respondents for studies that use this purpose (LeCompte \& Presissle, 1993).

The sampling used in this study was conducted using snowball sampling technique to obtain sample of respondents. Snowball sampling (also known as chain or network sampling) is the most commonly used form of sampling (Merriam, 2009). This technique involved finding some of the key respondents who easily met the criteria set out to participate in the study and then asked the respondent to introduce the researcher with other individuals who were potential respondents in the study.

This snowball sampling technique is useful for populations that are difficult to reach or identify individuals who meet sampling requirements or conditions but these populations know each other and are interrelated (Bernard, 2006). This method generates a sample of studies through referrals by those who share or know others who have the characteristics required of a study (Handcock \& Gile, 2011). Thus, the study sample will become larger when the information from the new sample can be identified to meet the specified sampling criteria (Patton, 2002).

In this study, the snowball sampling process was conducted by identifying several individuals who had autism children that met the criteria set out in the study as a 
preliminary sample, or also known as 'seed starting' (Shafie, 2010). This identification process requires researchers to obtain information from sources such as the NASOM, Social Welfare Department, General Hospital as well as local information from the public. The next step is to request a sample of the sample to identify other individuals who meet the criteria presented in this study and potentially respond.

In this study, the number of samples was final when no new individual was proposed that was not mentioned in the previous wave and fulfilled the respondents criteria set out in this study.

\section{RESULTS AND FINDINGS}

The findings of this study are divided into three sections namely the demographics of the respondents, the dissertation information and the responses provided by the respondents based on the semi-structured interviews conducted on the respondents.

\section{AUTISM TRACKING TEST}

When parents feel that some of their children may have autism, early detection tests should be performed. Early detection allows these children to be given the right therapy and to create a better quality of life for the individuals involved.

The M-CHAT Screening Test provided by the Public Health Doctoral Student, Faculty of Medicine, University of Malaya for Public Health Malaysia is a preliminary diagnostic test set for autism. It can be used to detect autism symptoms in infants as young as 18 months old.

This test consists of 23 sets of questions that parents should answer to children between the ages of 18 and 30 months. After answering all questions, the results will be emailed and can be used as a referral letter to the doctor for further examination and treatment.

This test is only an initial screening. If the results of the M-CHAT test are positive, parents should consult a doctor at the nearest health clinic for approval and discuss follow-up therapy or treatment (siraplimau.com, 2018).

\section{CONCLUSION}

Autism is a condition in which an individual experiences little developmental disruption. With early detection through parental observation, M-CHAT tests and referral to specialists, autism symptoms can still be developed through appropriate therapy and treatment.

The challenges parents face show that the process of raising autism children is not easy. It demands a great deal of sacrifice and patience. For example, parents have to 
deal with aggressive and hyperactive behaviors of children. If parents are not patient enough, then things might not work out.

Parents of autism children also need the support and understanding of the surrounding community. It's not just stopping the word sarcasm, but hopefully the community can accept the presence of autism children as well as other normal children. A caring and tolerant society should provide some relief to these parents.

In addition, governments, private organizations and related bodies need to hold more awareness programs on autism so that knowledge about these symptoms can be disseminated. The public needs to be exposed to the true information about autism so that the false myths can be stopped. Exposure to real information can also reduce misunderstandings aimed at autism children or their parents.

Concerns from all sides can ease the burden and sadness that parents have on these special children.

\section{TREATMent, MedicAl AND RehabiLItATION}

Dean of the Faculty of Traditional and Complementary Medicine at the University of Cyberjaya University of Medical Sciences, Associate Professor Dr Ibrahim Usman Mhaisker recommended that parents bring their 18-month-olds to a specialist if they find any abnormalities in their developmental development.

He also stressed that there is no permanent method for treating autism. However, if parents act early to seek treatment for their child, it will greatly help the child to develop self-confidence while living a better life.

The combination of several types of therapies or approaches such as speech, occupation, behaviour or learning therapy with the help of some medications such as homeopathy and Ayurveda is seen to enhance the positive development of these children (astroawani.com, 2017).

The Ministry of Health through the portal myhealth.gov.com said some people with autism are needed to help improve social skills, encourage more members to identify their behaviors, improve verbal and nonverbal communication skills and help families manage their situation calmly. .

There are no specific medications that can treat autism but there are some medications that can control the symptoms that may result from such problems as violent behavior, hyperactivity and extreme anxiety that may arise.

Children with autism need to undergo rehabilitation as a precautionary measure and preparation for their survival. Among the rehab activities they need to do are: 
- Speech and language therapy to improve communication skills among children.

- Occupational therapy (work recovery) so that social skills can be improved. These skills include eye-contact, focusing skills and helping children to better engage in daily activities. It is also intended to stimulate the capacity of the senses and the senses.

- Prevention of behavior is to control the heat of anger and violent reaction.

- Special education: Every autistic child needs to register with the Special Education Department, Ministry of Education so that their learning needs can be met. There are also non-governmental organizations providing learning facilities for children with autism. One is the National Autistic Society of Malaysia (NASOM).

- Disability Registration: Children with autism can register with the Social Welfare Department to get the help they need.

\section{Reference:}

American Psychiatric Association (2013). Diagnostic and Statistical Manual of Mental Disorder (5th Edition), Arlington, VA American Psychiatric Publishing

Center for Disease Control (CDC) (2013). Autism Spectrum Disorders (ASDs): Facts about ASDs.

Dr Eni Rahaiza Binti Muhamed Ramli (2008). Autism. Retrieved from http://www.myhealth.gov.my.

Dr M Ramzdhan (2019). Bagaimana Saya Boleh Mengenali Tanda-tanda Autism dan Apakah Punca Autisme? Retrieved from http://www.doctoroncall.com.my/soalan/punca-autisme

Dr Tjin Willy (2018). Diagnosis Autism. Retrieved from http://www.alodokter.com/autism/diagnosis

Hastings, R.P (2002). Parental Stress and Behaviour Problems of Children with Developmental Disability. Journal of Intellectual and Develomental Disability

Heiman, T. (2002). Parents of Children with Disabilities: Resilience, Coping and Future Expectation. Journal of Development and Physical Disabilities

Kanne, S.M and Mazure M.O (2011). Aggresion in Children and Adolescents with ASD: Prevelance and Risk Factors. Journal of Autism Developmental Disorder.

Lecavalier L, Leone S \& Wiltz J (2006). The Impact of Behavioural Problems on Caregivers Stress in Young People with ASD. Journal of Intellectual Disability.

McCarthy J (2007). Children with Autism Spectrum Disorders and Intellectual Disability. Current Opinion in Psychiatry.

Nazurah Hassan (2018). Autisme Boleh Dikesan Seawal 18 Bulan. Ini Cara Buat Saringan M-CHAT Secara Online. Retrieved from http://www.siraplimau.com

Paul R \& Kimberly G (2011). Development of Language and Communication. Textbook of Autism Spectrum Disorders, Arlington, American Psychiatric Publishing.

Punca Autism Mungkin Disebabkan Barang Rumah Ini? Retrieved from http://www.theasianparent.com/punca-autism

Rawatan Awal Bantu Kanak-kanak Autisme Jalani Kehidupan Lebih Baik. (17 Oktober 2017) Retrieved from http://www.astroawani.com/gaya-hidup/rawatan-awal-bantu-kanak-kanak-autismejalani-kehidupan-lebih-baik-158134 
Siti Nurshazwani, April (2018). Hari Kesedaran Autism Sedunia: 10 Perkara Anda Perlu Tahu Tentang Autism. Retrieved from http://www.astroawani.com

Utusan Online (1 Oktober 2017). Bantu Kanak-kanak Autism Berjaya. Retrieved from http://www.utusan.com.my/gaya-hidup/keluarga/bantu-kanak-kanak-autism-berjaya1.377222

Wawa Shauqi. 8 ciri Awal Bayi Autism. Retrieved from http://www.theproparenting.com 